\title{
Where does good quality qualitative health care research get published?
}

\author{
Jane C. Richardson ${ }^{1}$ and Jennifer Liddle ${ }^{2,{ }^{a}}$ \\ ${ }^{1}$ Senior Lecturer in Health Services Research, Research Institute for Primary Care and Health Sciences, Keele \\ University, Keele, Staffordshire, UK \\ ${ }^{2}$ Research Associate, Research Institute for Primary Care and Health Sciences, Keele University, Keele, Staffordshire, UK
}

\begin{abstract}
This short report aims to give some insight into current publication patterns for high-quality qualitative health research, using the Research Excellence Framework (REF) 2014 database. We explored patterns of publication by range and type of journal, by date and by methodological focus. We also looked at variations between the publications submitted to different Units of Assessment, focussing particularly on the one most closely aligned with our own research area of primary care. Our brief analysis demonstrates that general medical/health journals with high impact factors are the dominant routes of publication, but there is variation according to the methodological approach adopted by articles. The number of qualitative health articles submitted to REF 2014 overall was small, and even more so for articles based on mixed methods research, qualitative methodology or reviews/syntheses that included qualitative articles.
\end{abstract}

Key words: publishing; qualitative research; Research Excellence Framework (REF)

Received 5 January 2017; revised 7 March 2017; accepted 2 April 2017;

first published online 8 May 2017

\section{Introduction}

The title of this report is a question we are often asked, and ask ourselves, as social scientists using predominantly qualitative methods in an applied primary care research setting. ${ }^{1}$ The value of qualitative research in policymaking, service development and practice in medicine, in the study of health service organisation and delivery, and in enhancing understanding of health, illness and ageing is increasingly recognised (Casebeer and Verhoef, 1997; PLoS Medicine Editors, 2007; Godfrey, 2015). However, our experience and that

\footnotetext{
Correspondence to: Jane C. Richardson, Research Institute for Primary Care and Health Sciences, Keele University, Keele, Staffordshire ST5 5BG, UK. Email: j.c.richardson@keele.ac.uk

${ }^{\mathrm{a}}$ From February 2017: Senior Research Associate, Institute of Health and Society, Newcastle University.

${ }^{1}$ We recognise that social scientists use other methods and that qualitative methods are not the exclusive domain of social science.
}

of colleagues suggest that it is still difficult to get this type of research reviewed by and published in journals where it will be read by health care practitioners.

A previous study (Gagliardi and Dobrow, 2011) found that (between 1999 and 2008) very few qualitative studies were published in high impact health, medical and policy journals, compared with non-qualitative studies. The authors suggested possible reasons for this that required further exploration, including editorial policy and practice, quality of submissions and reviewers' understanding of how to assess qualitative research.

A 2015/16 'Twitterstorm' over the British Medical Journal's (BMJ) policy around qualitative research epitomised this struggle and led to over 80 academics submitting a letter to the $B M J$ inviting it to reconsider its policy (Greenhalgh et al., 2016). It is not within the scope of this article to report the full content of the Twitter debate (see https://storify.com/shereebekker/bmjnoqual and 
https://twitter.com/hashtag/BMJnoqual?src=hash), but useful to include this extract from the $B M J$ editors' response to Greenhalgh et al.'s letter:

'Arguably, though, the ideal place for publication of many qualitative papers will be journals that are targeted at the specialist audience for whom the findings are especially pertinent. Important qualitative research of a highly specialist nature may actually be overlooked if published in a general medical journal'.

(Loder et al., 2016)

The numerous contributions to the online discussions about the $B M J$ 's publication policy indicate that these topics are increasingly being debated in academic communities. Nonetheless, while it is recognised that few qualitative studies are published in high impact health journals, much less is known about where health researchers do publish qualitative research. The $B M J$ is not alone in its policy - as Greenhalgh et al. (2016) point out, many leading US medical journals (such as the Journal of the American Medical Association and the New England Journal of Medicine) also consider qualitative research a low priority.

We therefore aimed to explore the question 'Where does good quality health research using and exploring qualitative methods get published?', focussing particularly on our own area of primary care.

\section{Methods}

\section{Creating a database}

We used a publically available database created as part of the Research Excellence Framework (REF) 2014, a UK-based process of expert review, carried out in 36 subject-based Units of Assessment (UoAs). The results demonstrate the high quality and enhanced international standing of research conducted in UK universities. A submission comprises outputs, impact and environment: for our research we used outputs, defined as 'the product of any form of research, published between January 2008 and December 2013'. Up to four outputs can be submitted for each member of staff that an institution enters into the process. This means that the outputs are considered by individuals and their institutions to be of good quality.

Primary Health Care Research \& Development 2017; 18: 515-521
We used the Excel database on the REF website, searching the four UoAs that would include health research: clinical medicine (UoA1), primary care (UoA2), allied health care professionals (AHPs) (UoA3) and social policy (UoA22). We searched outputs using the following terms:

- 'qualitative' in article title or 'qualitative' in journal title

- any of the following terms in the article title: interview*, ethno*, experience*, focus group*, mixed method*, narrative*, photo*, video*.

These initial searches resulted in 1039 outputs (UoA1: 33/13400; UoA2: 152/4881; UoA3: 542/ 10358; UoA22: 312/4784) that were possibly qualitative research. While there were duplicates included in this figure, and not all of the outputs returned by the search were actually qualitative studies, these figures indicate that qualitative research represented around $3 \%$, at most, of the total (33 423) REF submissions in the four UoAs.

\section{Analysing the database}

Using the database of 1039 articles, the two authors (J.C.R., J.L.) assessed each output to determine whether it could be defined as qualitative and had a main focus on health. If these characteristics were not clear from the title, each author looked at the abstract independently to make a decision. If there was no agreement, the full text was accessed in order to make a decision. On this basis we excluded articles that focussed on gambling, fostering, education, migration, social work practice, cell biology, sexuality (where not linked to health), smoke alarms, domestic violence, and reasons for alcohol and drug use, but made the decision to include articles focussing on public health.

Following exclusions on this basis, 567 articles remained (UoA1: 12/33; UoA2: 122/152; UoA3: 352/542; UoA22: 81/312); 24 of these were duplicates (due to being submitted to more than one UoA). Our final database therefore comprised 543 unique articles.

The authors categorised each article (independently, then though joint agreement) according to its methodological approach as follows:

(a) Qualitative methods: research conducted using only qualitative methods. 
(b) Methodology: articles about how to do qualitative research, with the focus on methodology rather than findings.

(c) Mixed methods: including both quantitative and qualitative.

(d) Review or synthesis: which explicitly includes qualitative research articles.

\section{Results}

Table 1 illustrates the wide range of journals publishing good quality qualitative health research, and show that REF submissions included similar proportions of articles across social science health journals and other high impact health/medical journals. A high proportion of qualitative health articles submitted to REF 2014 were also published in nursing journals. Journals targeted at other specialist audiences and topics such as midwifery, cancer, health sociology and social care published fewer qualitative articles that were submitted to REF 2014.

Looking at publication title by UoA allows us to see further patterns (Table 2). UoA1 (medicine) included only $2 \%(n=12)$ of the REF qualitative health articles, in comparison with UoA22 (social policy) with $14 \%(n=81)$, UoA2 (primary care) with $22 \%(n=122)$ and the highest proportion of $62 \%(n=352)$ in UoA3 (AHPs).

UoA2 (primary care) includes the greatest proportion of articles published in both the $B M J$ (impact factor 19.967) and Social Science and Medicine (impact factor 2.814), while UoA3 (AHPs) includes the largest proportion of articles published in Qualitative Health Research (impact factor 1.403) and the Journal of Advanced Nursing (impact factor 1.917) as well as being the sole UoA to receive submitted articles published in the International Journal of Nursing Studies (impact factor 3.561).

Looking at the UoA that represents our own research setting (primary care, UoA2), other prominent publication outlets were the British Journal of General Practice (impact factor 2.741), PLoS ONE (impact factor 3.54) and Health Technology Assessment (impact factor 4.056).

Consideration of articles submitted to REF 2014 according to their methodological approach (Table 3 ) reveals that the majority $(412 ; 76 \%)$ were articles using only qualitative methods, 70 (13\%) were reviews or syntheses that explicitly included
Table 1 Journals with six or more qualitative health research articles entered in Research Excellence Framework (REF) 2014

\begin{tabular}{ll}
\hline Journal titles & $\begin{array}{l}\text { Unique } \\
\text { articles [n (\%)] }\end{array}$ \\
\hline Qualitative Health Research & $30(5.52)$ \\
BMJ & $26(4.79)$ \\
Social Science \& Medicine & $24(4.42)$ \\
International Journal of Nursing Studies & $21(3.87)$ \\
Journal of Advanced Nursing & $21(3.87)$ \\
BMJ Open & $13(2.39)$ \\
British Journal of General Practice & $13(2.39)$ \\
Palliative Medicine & $12(2.21)$ \\
Health Expectations & $9(1.66)$ \\
Journal of Clinical Nursing & $9(1.66)$ \\
Patient Education and Counseling & $9(1.66)$ \\
BMC Public Health & $8(1.47)$ \\
Health \& Social Care in the Community & $8(1.47)$ \\
Sociology of Health \& IIIness & $8(1.47)$ \\
PLoS ONE & $7(1.29)$ \\
Psycho-Oncology & $7(1.29)$ \\
BMC Health Services Research & $6(1.1)$ \\
European Journal of Cancer Care & $6(1.1)$ \\
Health & $6(1.1)$ \\
Health Technology Assessment & $6(1.1)$ \\
Midwifery & $6(1.1)$ \\
Supportive Care in Cancer & $6(1.1)$ \\
&
\end{tabular}

Table shows journals with six or more articles submitted to REF. In total, 184 journals included five or fewer articles that were submitted to REF 2014: six journals included five articles; six included four articles; 14 included three articles; 28 included two articles; 130 included one article.

qualitative research articles, $34(6 \%)$ included both qualitative and quantitative methods, while 27 (5\%) focussed on qualitative methodology rather than findings. The greatest proportion of articles submitted to REF 2014 that adopted only qualitative methods $(22 ; 5.34 \%)$ or focussed on qualitative methodology $(6 ; 22 \%)$ were published in Qualitative Health Research, while the greatest proportion of mixed methods articles were published in the $B M J$ (3; $9 \%)$ and the greatest proportion of reviews/ syntheses were published in the International Journal of Nursing Studies (4; 6\%) (Table 3).

In line with the overall figures for qualitative health submissions (Table 3), the majority of publications submitted in the primary care UoA were reporting research conducted using solely qualitative methods (Table 4). However, 34\% of the submissions in this UoA adopted other approaches, notably reviews/syntheses and mixed methods research. 
Table 2 Research Excellence Framework 2014 qualitative health submissions according to Units of Assessment (UoAs) and publication journal

\begin{tabular}{|c|c|c|c|c|c|}
\hline \multirow[b]{2}{*}{ Journals } & \multicolumn{4}{|l|}{ UoA } & \multirow[b]{2}{*}{ Total } \\
\hline & $\begin{array}{l}1 \text { (medicine) } \\
{[n(\% \text { within UoA)] }}\end{array}$ & $\begin{array}{l}2 \text { (primary care) } \\
{[n(\% \text { within UoA })]}\end{array}$ & $\begin{array}{l}3 \text { (AHPs) } \\
{[n(\% \text { within UoA) }]}\end{array}$ & $\begin{array}{l}22 \text { (social policy) } \\
{[n(\% \text { within UoA })]}\end{array}$ & \\
\hline$B M J$ & $6(50)$ & $18(14.75)$ & $4(1.14)$ & $4(4.94)$ & 32 \\
\hline Qualitative Health Research & $0(0)$ & $4(3.28)$ & $25(7.1)$ & $1(1.23)$ & 30 \\
\hline Social Science \& Medicine & $0(0)$ & $13(10.66)$ & $9(2.56)$ & $5(6.17)$ & 27 \\
\hline $\begin{array}{l}\text { International Journal of Nursing } \\
\text { Studies }\end{array}$ & $0(0)$ & $0(0)$ & $22(6.25)$ & $0(0)$ & 22 \\
\hline Journal of Advanced Nursing & $0(0)$ & $2(1.64)$ & $17(4.83)$ & $3(3.7)$ & 22 \\
\hline BMJ Open & $1(8.33)$ & $3(2.46)$ & $9(2.56)$ & $1(1.23)$ & 14 \\
\hline British Journal of General Practice & $0(0)$ & $8(6.56)$ & $4(1.14)$ & $1(1.23)$ & 13 \\
\hline Palliative Medicine & $0(0)$ & $0(0)$ & $12(3.41)$ & $0(0)$ & 12 \\
\hline Health Expectations & $0(0)$ & $1(0.82)$ & $7(1.99)$ & $1(1.23)$ & 9 \\
\hline Health Technology Assessment & $1(8.33)$ & $4(3.28)$ & $4(1.14)$ & $0(0)$ & 9 \\
\hline Journal of Clinical Nursing & $0(0)$ & $0(0)$ & $8(2.27)$ & $1(1.23)$ & 9 \\
\hline Patient Education and Counseling & $0(0)$ & $3(2.46)$ & $5(1.42)$ & $1(1.23)$ & 9 \\
\hline BMC Public Health & $0(0)$ & $2(1.64)$ & $4(1.14)$ & $2(2.47)$ & 8 \\
\hline $\begin{array}{l}\text { Health \& Social Care in the } \\
\text { Community }\end{array}$ & $0(0)$ & $0(0)$ & $2(0.57)$ & $6(7.41)$ & 8 \\
\hline PLOS ONE & $0(0)$ & $5(4.1)$ & $3(0.85)$ & $0(0)$ & 8 \\
\hline Sociology of Health \& IIIness & $0(0)$ & $2(1.64)$ & $4(1.14)$ & $2(2.47)$ & 8 \\
\hline Psycho-Oncology & $0(0)$ & $0(0)$ & 7 (1.99) & $0(0)$ & 7 \\
\hline Total & $12(100)$ & $122(100)$ & $352(100)$ & $81(100)$ & \\
\hline
\end{tabular}

$\mathrm{AHP}=$ allied health care professionals.

Figures in brackets show the percentage within each UoA represented by that number of articles.

Total do not add up as the table does not show every journal.

Table shows journals with six or more articles submitted to REF. In total, 184 journals included five or fewer articles that were submitted to REF 2014: six journals included five articles; six included four articles; 14 included three articles; 28 included two articles; 130 included one article.

\section{Discussion and implications}

The overall conclusion from our brief exploration of where high-quality qualitative health research is published is that general medical or health journals with high impact factors are the dominant routes of publication, but that there is variation according to the methodological approach adopted by articles. The number of qualitative health articles submitted to REF 2014 overall is small, and even more so for articles based on mixed methods research, qualitative methodology or reviews/syntheses that included qualitative articles. There is also great disparity between the proportions of qualitative health publications submitted to REF 2014 in each of the four UoAs, despite each covering a broad range of topics and issues amenable to research using qualitative methods.

Within the primary care UoA that represents our own research setting, and comprises $22 \%$ of the qualitative health research submitted to REF 2014 , over $30 \%$ of submissions were published in one of the three journals (BMJ, Social Science \& Medicine, British Journal of General Practice). Encouragingly, over a third of the qualitative health submissions to the primary care UoA were publications of reviews/syntheses, mixed methods research or articles about qualitative methodology. However, there was a general paucity of research using mixed methods or focussing on qualitative methodology or reviews/ syntheses of qualitative papers across the four UoAs. We would argue that these areas are as important as 'standard' research using qualitative methods. First, there are many examples of the benefits of mixed methods research in gaining a fuller understanding of a phenomenon (see, eg, Yardley and Bishop, 2015), and in helping 'to characterise complex healthcare systems, identify the mechanisms of complex problems $[\ldots]$ and 
Table 3 Journals with six or more qualitative health research articles entered in Research Excellence Framework 2014 categorised by methodological approach

\begin{tabular}{|c|c|c|c|c|c|}
\hline \multirow[b]{2}{*}{ Journals } & \multicolumn{4}{|c|}{ Methodological approach } & \multirow[b]{2}{*}{ Total } \\
\hline & $\begin{array}{l}\text { Qualitative methods } \\
\text { [n }(\% \text { within each } \\
\text { journal)] }\end{array}$ & $\begin{array}{l}\text { Methodology } \\
{[n(\% \text { within }} \\
\text { each journal)] }\end{array}$ & $\begin{array}{l}\text { Mixed methods } \\
{[n(\% \text { within each }} \\
\text { journal)] }\end{array}$ & $\begin{array}{l}\text { Review/synthesis } \\
{[n(\% \text { within each }} \\
\text { journal)] }\end{array}$ & \\
\hline Qualitative Health Research & $22(73.33)$ & $6(20)$ & $0(0)$ & $2(6.67)$ & $30(100)$ \\
\hline$B M J$ & $21(80.77)$ & $1(3.85)$ & $3(11.54)$ & $1(3.85)$ & $26(100)$ \\
\hline Social Science \& Medicine & $21(87.5)$ & $0(0)$ & $1(4.17)$ & $2(8.33)$ & $24(100)$ \\
\hline $\begin{array}{l}\text { International Journal of } \\
\text { Nursing Studies }\end{array}$ & $16(76.19)$ & $0(0)$ & $1(4.76)$ & $4(19.05)$ & $21(100)$ \\
\hline Journal of Advanced Nursing & 17 (80.95) & $0(0)$ & $1(4.76)$ & $3(14.29)$ & $21(100)$ \\
\hline BMJ Open & $12(92.31)$ & $0(0)$ & $0(0)$ & $1(7.69)$ & $13(100)$ \\
\hline $\begin{array}{l}\text { British Journal of General } \\
\text { Practice }\end{array}$ & $11(84.62)$ & $0(0)$ & $1(7.69)$ & 1 (7.69) & $13(100)$ \\
\hline Palliative Medicine & $10(83.33)$ & $1(8.33)$ & $0(0)$ & $1(8.33)$ & $12(100)$ \\
\hline Health Expectations & 7 (77.78) & $0(0)$ & $0(0)$ & $2(22.22)$ & $9(100)$ \\
\hline Journal of Clinical Nursing & 7 (77.78) & $1(11.11)$ & $0(0)$ & $1(11.11)$ & $9(100)$ \\
\hline $\begin{array}{l}\text { Patient Education and } \\
\text { Counseling }\end{array}$ & $7(77.78)$ & $0(0)$ & $0(0)$ & $2(22.22)$ & $9(100)$ \\
\hline BMC Public Health & $5(62.5)$ & $0(0)$ & $1(12.5)$ & $2(25)$ & $8(100)$ \\
\hline $\begin{array}{l}\text { Health \& Social Care in the } \\
\text { Community }\end{array}$ & $5(62.5)$ & $0(0)$ & $0(0)$ & $3(37.5)$ & $8(100)$ \\
\hline Sociology of Health \& IIIness & $7(87.5)$ & $1(12.5)$ & $0(0)$ & $0(0)$ & $8(100)$ \\
\hline PLOS ONE & $6(85.71)$ & $1(14.29)$ & $0(0)$ & $0(0)$ & $7(100)$ \\
\hline Psycho-Oncology & $5(71.43)$ & $0(0)$ & $0(0)$ & $2(28.57)$ & $7(100)$ \\
\hline $\begin{array}{l}\text { BMC Health Services } \\
\text { Research }\end{array}$ & $5(83.33)$ & $0(0)$ & $1(16.67)$ & $0(0)$ & $6(100)$ \\
\hline $\begin{array}{l}\text { European Journal of Cancer } \\
\text { Care }\end{array}$ & $3(50)$ & $0(0)$ & $1(16.67)$ & $2(33.33)$ & $6(100)$ \\
\hline Health & $4(66.67)$ & $0(0)$ & $1(16.67)$ & $1(16.67)$ & $6(100)$ \\
\hline $\begin{array}{l}\text { Health Technology } \\
\text { Assessment }\end{array}$ & $2(33.33)$ & $0(0)$ & $2(33.33)$ & $2(33.33)$ & $6(100)$ \\
\hline Midwifery & $4(66.67)$ & $1(16.67)$ & $0(0)$ & $1(16.67)$ & $6(100)$ \\
\hline Supportive Care in Cancer & $6(100)$ & $0(0)$ & $0(0)$ & $0(0)$ & $6(100)$ \\
\hline
\end{tabular}

Figures in brackets show the percentages within each journal of each methodological category.

Table shows journals with six or more articles submitted to REF. In total, 184 journals included five or fewer articles that were submitted to REF 2014: six journals included five articles; six included four articles; 14 included three articles; 28 included two articles; 130 included one article.

understand aspects of human interaction such as communication, behaviour and team performance' (Hansen et al., 2016). Second, publications that focus on qualitative methodology are important in advancing the field, taking advantage of new areas and encouraging the conduct of high-quality research. Third, it has been suggested that metasyntheses of qualitative evidence might give qualitative research a stronger role in decisionmaking (Gagliardi and Dobrow, 2011), uncover new understandings and be useful for practitioners (Seers, 2015).

There are, of course limitations to our findings and interpretations. We have taken submission to
REF as a proxy for quality, whereas publications may be submitted (or not) to REF for reasons other than quality alone. It is also not possible to know how individual publications were rated in REF 2014, only how an overall submission was judged.

If REF 2014 is indeed a true reflection of the high-quality qualitative health research being conducted by UK universities, then this indicates either that other types of qualitative research (methodological, mixed methods research and reviews/syntheses) are not frequently taking place or that this research is not considered to be of sufficient quality to be submitted to REF. 
Table 4 Publications submitted to Research Excellence Framework 2014 categorised according to Units of Assessment (UoAs) and methodological approach

\begin{tabular}{|c|c|c|c|c|c|}
\hline \multirow[b]{2}{*}{ Methodological approaches } & \multicolumn{4}{|l|}{ UoA } & \multirow[b]{2}{*}{ Total } \\
\hline & $\begin{array}{l}1 \text { (medicine) } \\
{[n(\% \text { within UoA) }]}\end{array}$ & $\begin{array}{l}2 \text { (primary care) } \\
{[n(\% \text { within UoA)] }}\end{array}$ & $\begin{array}{l}3 \text { (AHPs) } \\
{[n(\% \text { within UoA)] }}\end{array}$ & $\begin{array}{l}22 \text { (social policy) } \\
{[n(\% \text { within UoA)] }}\end{array}$ & \\
\hline Qualitative methods & $10(83.33)$ & $81(66.39)$ & $267(75.85)$ & $71(87.65)$ & $429(75.66)$ \\
\hline Methodology & $1(8.33)$ & $5(4.1)$ & $17(4.83)$ & $4(4.94)$ & $27(4.76)$ \\
\hline Mixed methods & $1(8.33)$ & $15(12.3)$ & $20(5.68)$ & $2(2.47)$ & $38(6.7)$ \\
\hline Review/synthesis & $0(0)$ & $21(17.21)$ & $48(13.64)$ & $4(4.94)$ & 73 (12.87) \\
\hline Total & $12(100)$ & $122(100)$ & $352(100)$ & $81(100)$ & $567(100)$ \\
\hline
\end{tabular}

$\mathrm{AHP}=$ allied health care professionals.

Figures in brackets show the percentages in each UoA of each methodological category.

A similar line of reasoning can, of course, be taken regarding the specific journals that feature in REF submissions.

The data in this short report provide an insight into the publication patterns for high-quality qualitative health research submitted to REF 2014. However, it also raises more questions than it is able to answer for those involved in health research:

(1) If the value of qualitative (and mixed methods) research is increasingly recognised, why was there a low number of qualitative health articles submitted to REF 2014 overall, and, in particular, why was there a lower representation of articles reporting mixed methods, qualitative methodological research or reviews/syntheses?

(2) Does the balance in REF 2014 between qualitative health research published in high impact general medical journals and that published in more specialist journals reflect the broader picture of where high-quality qualitative health research is published per se or is there high-quality research published in less prominent, specialist, journals that is consequently perceived as less suitable for submission to REF?

(3) Why is there such a disparity between the proportions of qualitative health research submitted to each of the four healthrelated UoAs?

Of course, patterns of publication change over time with changes to journal policies (eg, the $B M J)$ and the emergence of new journals (eg, the launches of $P L O S O N E^{2}$ in 2006 and $B M J$ Open in 2011). The next REF exercise may see changes to the patterns we have identified and reflect the whole range of good quality research that seeks to understand the complex nature of illness and health care.

\section{Acknowledgements}

The authors thank Rebecca Whittle for help with analysis of the database.

\section{Financial Support}

This research received no specific grant from any funding agency, commercial or not-for-profit sectors.

\section{Conflicts of Interest}

None.

\section{References}

Casebeer, A.L. and Verhoef, M.J. 1997: Combining qualitative and quantitative research methods: considering the possibilities for enhancing the study of chronic diseases. Chronic Diseases in Canada 18, 130-35.

Gagliardi, A.R. and Dobrow, M.J. 2011: Paucity of qualitative research in general medical and health services and policy

${ }^{2}$ PLOS ONE is the world's largest journal by number of papers published (about $30000 /$ year or 85 papers/day) (Wikipedia). 
research journals: analysis of publication rates. BMC Health Services Research 11, 268.

Godfrey, M. 2015: Qualitative research in age and ageing: enhancing understanding of ageing, health and illness. Age and Ageing 44, 726-27.

Greenhalgh, T., et al. 2016: An open letter to the BMJ editors on qualitative research. BMJ 352, i563.

Hansen, M., O'Brien, K., Meckler, G., Chang, A.M. and Guise, J-M. 2016: Understanding the value of mixed methods research: the Children's Safety InitiativeEmergency Medical Services. Emergency Medicine Journal 33, 489-94.
Loder, E., Groves, T., Schroter, S., Merino, J.G. and Weber, W. 2016: Qualitative research and the BMJ. BMJ 352, i641.

PLoS Medicine Editors 2007: Qualitative research: understanding patients' needs and experiences. PLoS Medicine 4, e258.

Seers, K. 2015: Qualitative systematic reviews: their importance for our understanding of research relevant to pain. British Journal of Pain 9, 36-40.

Yardley, L. and Bishop, F.L. 2015: Using mixed methods in health research: benefits and challenges. British Journal of Health Psychology 20, 1-4. 